\title{
A Study on Pre-Induction Cervical Ripening with PGE2 Vaginal Tablet One (3 mg) vs. Half (1.5 mg) in Low Risk Multi Parous Mothers at 40 Weeks of Gestation
}

\author{
Naleen Ratnayake ${ }^{1}$, Ahangama Arachchige Nilanga Nishad ${ }^{2}$, \\ Yahampath Arachchige Gamini Perera1, Devasuriya Pathinayakalage Lanka Rasanjana1, \\ Samarakoon Mudiyanselage Sameera Gayanath Gunarathna ${ }^{3}$, \\ Prabath Kularathna Abeysundara² \\ ${ }^{1}$ Castle Street Hospital for Women, Colombo, Sri Lanka \\ ${ }^{2}$ Center for Epidemiological and Clinical Research LK, Colombo, Sri Lanka \\ ${ }^{3}$ Worthing Hospital (NHS), Western Sussex, UK \\ Email: ^aanilanga@gmail.com
}

How to cite this paper: Ratnayake, N., Nishad, A.A.N, Perera, Y.A.G., Rasanjana, D.P.L., Gunarathna, S.M.S.G. and Abeysundara, P.K. (2021) A Study on Pre-Induction Cervical Ripening with PGE2 Vaginal Tablet One $(3 \mathrm{mg})$ vs. Half $(1.5 \mathrm{mg})$ in Low Risk Multi Parous Mothers at 40 Weeks of Gestation. Open Journal of Obstetrics and Gynecology, 11, 1005-1012.

https://doi.org/10.4236/ojog.2021.118094

Received: May 8, 2021

Accepted: August 14, 2021

Published: August 17, 2021

Copyright $\odot 2021$ by author(s) and Scientific Research Publishing Inc. This work is licensed under the Creative Commons Attribution International License (CC BY 4.0).

http://creativecommons.org/licenses/by/4.0/

\begin{abstract}
Backgrounds: Induction of labor is a common practice. In women with immature cervix, PGE2 is commonly used for pre-induction. We hypothesized that PGE2 $1.5 \mathrm{mg}$ may be equally effective to PGE2 $3 \mathrm{mg}$ in multiparous women for labor induction. The present effort was an attempt to compare the efficacy and effects of pre-induction cervical ripening with PGE2 $3 \mathrm{mg}$ vs. 1.5 $\mathrm{mg}$ in multi-parous mothers (2nd and 3rd Pregnancy) at 40 weeks. Methods: A double-blind randomized controlled trial was carried out at Castle Street Hospital for Women, Colombo, Sri Lanka. Study subjects consisted of women with singleton pregnancy (no cesarean history) admitted for delivery at 40 weeks of their $2^{\text {nd }}$ or 3 rd pregnancy. PGE2 $1.5 \mathrm{mg}$ vs. $3 \mathrm{mg}$ PGE2 vaginal tablet were used for treatment $(\mathrm{n}=173)$ and control $(\mathrm{n}=170)$ groups, respectively. Cervical ripening and maternal, fetal complications were observed. Unfavorable cervices were induced with the same PGE2 dose in the following day. Results: Study group, compared with the control group, achieved the same rate of favorable cervices in 1 st and 2 nd cycles $(63.5 \%$ vs. $64 \%$, respectively). Both groups showed the same rate of cervical dilatation achievement, and admissions to Special Care Baby Unit. Study group showed significantly less maternal complications ( $4 \%$ and $11 \%$, respectively: $\mathrm{p}=0.01$ ). Conclusion: PGE2 of $1.5 \mathrm{mg}$ is equally effective in achieving favorable cervices, adequate cervical dilatation with minimum maternal complications compared to the usual $3 \mathrm{mg}$ dose in multiparous low-risk women.
\end{abstract}


Keywords

Pregnancies, PGE2

\section{Introduction}

Induction of labor is defined as the process of artificially stimulating the uterus to start labour and to $25 \%$ of all deliveries at term ended up with induction of labour [1] [2]. Before the initiation of labor, many biochemical changes take place in the connective tissue of the lower uterine segment and the cervix [3]. In the absence of a ripen or favorable cervix, a successful vaginal birth is less likely [4] [5].

Assessment is accomplished by calculating a Modified Bishop score [6] [7]. Cervical ripening agents are used for labor induction and Prostaglandins are studied extensively as for the agents for the cervical ripening [8] [9].

Risks associated with the use of prostaglandins in the mother include uterine hyper stimulation, nausea, vomiting, diarrhea, and fever. Uterine hyper stimulation was considered present if the contraction frequency is more than five in 10 minutes or if a contraction exceeded 2 minutes in duration with associated fetal heart rate abnormality presence [10]. There is a less chance of uterine hyper stimulation after low-dose prostaglandin E2 therapy. Studies with $1.5 \mathrm{mg}$ PGE2 gel have shown promising results with effective cervical ripening with low side effects profile, but $1.5 \mathrm{mg}$ of tablet has not been studied which is a less expensive alternative [11].

Half a tablet dose (1.5 mg) may be adequate for the low body mass index [12] (BMI) containing Asian population and especially as multi parous cervices are likely to respond better than primigravidae. Therefore, the aim of this study was to compare the efficacy of the half tablet of PGE2 $(1.5 \mathrm{mg})$ with regard to ripening of the cervix, and to compare the side effects.

Usual practice is to carry out elective cervical ripening at 40 weeks [13] [14] [15].

Majority of studies confirm the more potent action of prostaglandins with regard to cervical ripening and multi parous patients have shown better response to the prostaglandins than primi gravid patients [16]-[21]. Because of this better response of multipara to the PGE2, this study was planned to evaluate the effectiveness of low dose of PGE2 for the pre-induction cervical ripening in multipara.

Objectives of this study were to compare the efficacy and effects of pre-induction cervical ripening, change in Modified Bishop's Score in 6 hours after insertion of PGE2 to a score of 7, the incidences of achievement of cervical dilatation to 8 $\mathrm{cm}$, time taken to achieve cervical dilatation of $8 \mathrm{~cm}$ and to compare fetal and maternal complications with PGE2 $3 \mathrm{mg}$ vs. $1.5 \mathrm{mg}$ ) in two groups of multi parous mothers ( $2^{\text {nd }} \& 3^{\text {rd }}$ Pregnancy) at 40 weeks of gestation. 


\section{Materials and Method}

It is a double blind randomized controlled study and the study was carried out at ward 06 Castle street hospital for women, Colombo a tertiary care hospital of Sri Lanka, forone and half year period starting from May 2014.

This project proposal was submitted to the ethical review committee of the University of Kelaniya and approval was obtained. Informed written consent taken from all the patients that enter into the study, who were admitted for confinement at the 40 weeks of gestation, with singleton gestation in their second or third pregnancy with previous normal vaginal delivery.

Pregnant mothers without having regular clinic follow up records, Pregnant mothers with preexisting medical disorders, mothers who had adverse pregnancy outcomes, mothers with multiple pregnancies, mothers with congenital uterine abnormalities or large fibroids distorting the normal uterine architecture, prior caesarian delivery, mothers with any contraindication for vaginal delivery, mal presentations, extremes of BMI, were excluded from the study.

Inclusion criteria were live, singleton second or third pregnancy at 40 weeks of gestation with previous vaginal delivery with confirmed dates in early pregnancy by ultra sound scan, cephalic presentation, intact membranes, unfavorable cervix (Modified Bishops score $\leq 5$ ), normal fetal well-being confirmed by CTG (cardiotocography) and AFI (amniotic fluid index) assessment within 6 hours, before administration of prostaglandins.

PGE2 3 mg group considered as control group $(n=170)$ and PGE2 $1.5 \mathrm{mg}$ inserted group considered as Study group $(n=173)$. After $1^{\text {st }}$ PGE2 insertion, 6 hours later vaginal examination was performed to assess cervix and if cervix is not favorable and if mother not gone into labor during the day, in following day 24 hours after insertion of first dose of PGE2, again vaginal assessment will be performed before insertion of the second dose of the PGE2. After insertion of the $1^{\text {st }}$ dose of PGE2, $1^{\text {st }} 24$ hour period will be the $1^{\text {st }}$ cycle and after the $2^{\text {nd }}$ dose of PGE2 next 24-hour period will be the $2^{\text {nd }}$ cycle. If Modified Bishops Score has reached 7 or more, the patients were induced by ARM (artificial rupture of membranes) and Oxytocin infusion. If they go into labour, routine labour room care and monitoring were done (Figure 1).

Incidences and mean durations in the two groups were calculated with $95 \%$ confidence intervals. Comparisons were calculated using students sample t tests for numerical and continuous variables. Chi-squared tests were carried out for the categorical outcomes. Multiple logistic regressions were carried out whenever necessary to get the confounding factors. Significance was considered at 95\% level.

\section{Results}

Mean age in the control group was $28.12 \pm 4.85$ years while it was $28.84 \pm 6.41$ years in the study group. The study participants in cases and control groups were equal in the basic characteristics because no statistically significant difference was shown in two groups (Table 1, Table 2). 


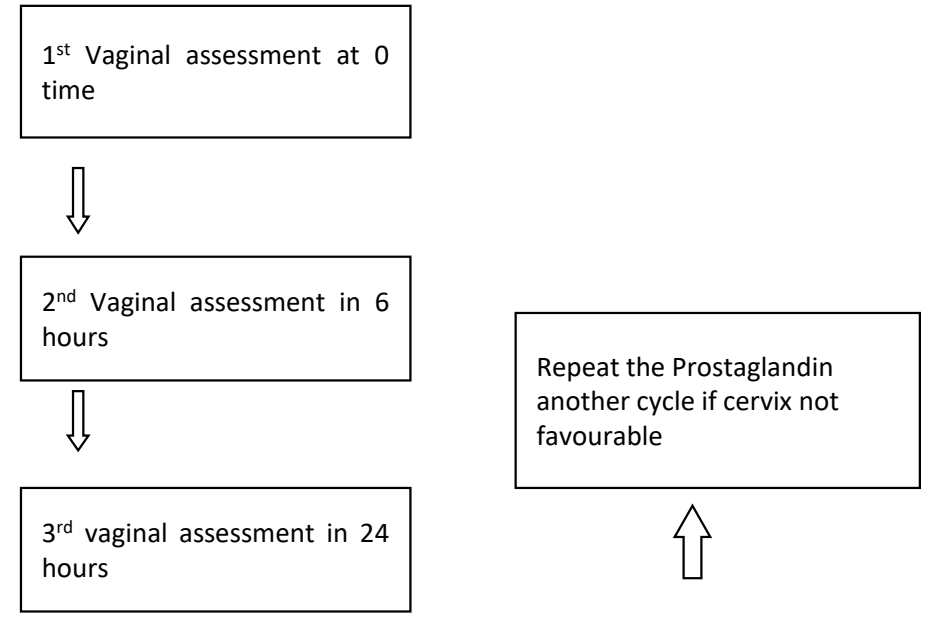

Figure 1. Flow chart to show the protocol for PGE 2 insertion in intervention and control groups.

Table 1. Basic characteristics of the study participants.

\begin{tabular}{|c|c|c|c|c|c|}
\hline & \multicolumn{2}{|c|}{ Control group } & \multicolumn{2}{|c|}{ Study group } & Significance \\
\hline & \multicolumn{2}{|c|}{ Mean \pm SD } & \multicolumn{2}{|c|}{ Mean \pm SD } & $P$ value \\
\hline Age (years) & \multicolumn{2}{|c|}{$28.12 \pm 4.85$} & \multicolumn{2}{|c|}{$28.84 \pm 6.41$} & 0.785 \\
\hline Height $(\mathrm{cm})$ & \multicolumn{2}{|c|}{$156.13 \pm 9.34$} & \multicolumn{2}{|c|}{$155.35 \pm 10.5$} & 0.875 \\
\hline \multirow[t]{2}{*}{ Weight (kg) } & \multicolumn{2}{|c|}{$59.61 \pm 12.40$} & \multicolumn{2}{|c|}{$59.23 \pm 12.64$} & 0.97 \\
\hline & Number & $\%$ & Number & $\%$ & \\
\hline \multicolumn{6}{|l|}{ Parity } \\
\hline $2^{\text {nd }}$ pregnancy & 128 & 75.29 & 132 & 76.30 & \\
\hline $3^{\text {rd }}$ pregnancy & 42 & 24.70 & 41 & 23.69 & \\
\hline \multicolumn{6}{|l|}{ Education level } \\
\hline Below grade 8 & 27 & 15.88 & 26 & 15.02 & \\
\hline Below $\mathrm{O} / \mathrm{L}$ & 91 & 53.52 & 95 & 54.91 & \\
\hline Below A/L & 25 & 14.70 & 26 & 14.45 & \\
\hline Above A/L & 27 & 15.88 & 26 & 15.02 & \\
\hline
\end{tabular}

${ }^{\star}$ O/L-G.C.E. Ordinary Level, ${ }^{\star *}$ A/L G.C.E. Advanced level.

Table 2. Comparison of cases and control group efficacy and complications.

\begin{tabular}{|c|c|c|c|c|c|c|}
\hline & & \multicolumn{2}{|c|}{ Control group } & \multicolumn{2}{|c|}{ Study group } & \multirow{2}{*}{$\begin{array}{c}\text { Sig. } \\
p\end{array}$} \\
\hline & & Number & $\%$ & Number & $\%$ & \\
\hline \multirow{2}{*}{$\begin{array}{l}\text { Modified Bishops Score } 6 \text { hours after PGE2 } \\
\text { insertion in first cycle. }\end{array}$} & Modified Bishops Score less than 7 & 142 & 83.52 & 144 & 83.23 & \multirow[t]{2}{*}{1} \\
\hline & Modified Bishops Score more than 7 & 28 & 16.47 & 29 & 16.76 & \\
\hline \multirow{2}{*}{6 hours after PGE2 insertion in second cycle } & Modified Bishops Score less than 7 & 90 & 78.26 & 92 & 78.63 & \multirow[t]{2}{*}{1.01} \\
\hline & Modified Bishops Score more than 7 & 25 & 21.73 & 24 & 21.36 & \\
\hline \multirow{2}{*}{$\begin{array}{l}\text { Incidences of achieving cervical dilatation of } \\
8 \mathrm{~cm} \text { during labor. }\end{array}$} & Dilated to $8 \mathrm{~cm}$ & 133 & 78.23 & 142 & 82.08 & \multirow[t]{2}{*}{0.42} \\
\hline & Not dilated & 37 & 21.76 & 31 & 17.91 & \\
\hline \multirow{2}{*}{$\begin{array}{l}\text { Time taken to achieve cervical dilatation of } \\
8 \mathrm{~cm} \text { during labor. }\end{array}$} & Less than 8 hours & 92 & 54.11 & 89 & 51.44 & \multirow[t]{2}{*}{0.67} \\
\hline & More than 8 hours & 78 & 45.88 & 84 & 48.55 & \\
\hline
\end{tabular}




\begin{tabular}{|c|c|c|c|c|c|c|}
\hline \multicolumn{7}{|l|}{ Continued } \\
\hline \multirow{2}{*}{ Admission to SCBU (special care baby unit) } & SCBU admitted & 27 & 15.88 & 29 & 16.76 & \multirow[t]{2}{*}{0.88} \\
\hline & Not admitted & 143 & 84.11 & 144 & 83.23 & \\
\hline \multirow{2}{*}{ Maternal complications } & Complications present & 19 & 11.17 & 7 & 4.04 & \multirow[t]{2}{*}{0.01} \\
\hline & Complications not present & 151 & 88.82 & 166 & 95.95 & \\
\hline
\end{tabular}

${ }^{*}$ PGE2-Prostaglandin E2, ${ }^{*}$ SCBU-Special care baby unit.

There were 28 mothers (16.47\%) of control group \& 29 mothers $(16.76 \%)$ in study group with ripening of cervix (modified Bishop's score more than or equal to 7) with favorable for induction in 6 hours after PGE2 insertion in first cycle. There were no statistically significant differences between 6 hours after post PGE2 insertion in modified Bishop's scores in the study and control groups during the first cycle. 27 mothers in the control group and 28 mothers in the study group went into labor before insertion of the $2^{\text {nd }}$ dose of PGE2 in the following day.

There were 25 mothers $(21.73 \%)$ of control group \& 24 mothers $(21.36 \%)$ in study group achieved ripening of cervix (modified Bishop's score equal or more than 7) in 6 hours after PGE2 insertion in second cycle. There were no statistically significant differences between 6 hours after post PGE2 insertion in modified Bishop's scores in the study and control groups during the second cycle.

There were 142 mothers $(82.08 \%)$ of study group \& 133 mothers $(78.23 \%)$ in control group with incidences of achieving cervical dilatation of $8 \mathrm{~cm}$ during labor. There were no statistically significant differences between incidences of achieving cervical dilatation of $8 \mathrm{~cm}$ during the labor in the study and control groups.

There were 89 mothers (51.44\%) of study group and 92 mothers $(54.11 \%)$ in control group achieved cervical dilatation of $8 \mathrm{~cm}$ during labor in less than 8 hours. There were 84 mothers $(48.55 \%)$ of study group \& 78 mothers $(45.88 \%)$ in control group achieved cervical dilatation of $8 \mathrm{~cm}$ during labor in more than 8 hours. There were no statistically significant differences between time taken to achieve cervical dilatation of $8 \mathrm{~cm}$ during the labor in the study and control groups.

There were $16.76 \%$ of study group \& $15.88 \%$ in control group had admitted to the SCBU following delivery. There is no statistically significant difference with regarding to admission to Special Care Baby Unit at delivery between these two groups.

Maternal complications (nausea, vomiting, headache, hyperthermia, hyperstimulation) were higher in the control group and chi square value was 6.22 and it showed significantly low level of maternal complications with low dose PGEs in relation to the standard dose PGE2.

Study group with 1.5 mg PGE2 has statistically significant reduced number of maternal complications than the control group.

\section{Discussion}

There were no significant differences in achieving modified Bishop's scores of 
more than 7 (favorable cervices) in 6 hours following the $1^{\text {st }}$ and $2^{\text {nd }}$ cycles of PGE2 insertions in the study and control groups. There was no statistically significant difference between incidences of achieving cervical dilatation of $8 \mathrm{~cm}$ during the labor in the study and control groups too. Upper limit of $8 \mathrm{~cm}$ cervical dilatation taken as a cutoff point to assess rate of cervical dilatation in these two groups. No statistically significant difference observed between time taken to achieve cervical dilatation of $8 \mathrm{~cm}$ during the labor in the study and control groups. Thus, PGE2 $1.5 \mathrm{mg}$ dosage is equally effective to the PGE2 $3 \mathrm{mg}$ dosage in low risk multi parous women. Further the complication rates were lower in the study group in comparison to the control group.

\section{Conclusion}

In conclusion, $1.5 \mathrm{mg}$ of Dinoprostone (half a tablet) is equally effective to $3 \mathrm{mg}$ of Dinoprostone (one tablet). Considering low side effect profile and low cost to the health care system, with similar efficacy to the $3 \mathrm{mg}$ PGE2 tablet, $1.5 \mathrm{mg}$ PGE2 tablet is recommended for practice as an effective method.

\section{Acknowledgements}

Medical officers and Nursing staff of ward 06 and all the pregnant mothers CSHW for their participation.

\section{Funding}

There is no funding.

\section{Conflicts of Interest}

Authors have no competing interests.

\section{References}

[1] WHO (2018) Recommendations: Induction of Labour at or Beyond Term. World Health Organization, Geneva.

[2] WHO (2017) Managing Complication in Pregnancy and Childbirth: A Guide for Midwives and Doctors. World Health Organization, Geneva.

[3] Huszar, G., Cabrol, D. and Naftolin, F. (2020) The Relationship between Myometrial Contractility and Cervical Maturation in Pregnancy and Labor. Medicine, Dentistry, Nursing \& Allied Health, 2, $10 \mathrm{p}$.

[4] Alfirevic, Z., Baxter, J., Calder, A., Green, J., Markham, C., Shehata, H., McCormick, C. and Hill, S.S. (2008) Nice clinical guidelines, Induction of Labor. RCOG Press, London.

[5] Batista, L., Chung, J.H., Lagrew, D.C. and Wing, D.A. (2007) Complications of Labor Induction among Multiparous Women in a Community Based Hospital System. American Journal of Obstetrics \& Gynaecology, 197, 241.

[6] Bishop, E.H. (1964) Pelvic Scoring for Elective Induction. Obstetrics and Gynaecology, 24, 266-267.

[7] Hughey, M.J., Mcelin, T.W. and Bird, C.C. (1976) An Evaluation of Pre Induction 
Scoring Systems. Obstetrics and Gynaecology, 48, 635-641.

[8] Sahar, H., Katariina, L., Erik, F., Niveen, M.E., Abu-Rmeileh, H.Y., Ali-Masri, M.Z., Kaled, Z., Åse, V. and Khaled, M.I. (2019) Induction of Labor among Singleton Pregnancies in Six Palestinian Governmental Hospitals: A Population-Based Cohort Study. International Journal of Women's Health, 11, 597-605. https://doi.org/10.2147/IJWH.S215781

[9] Joscha, R., Roberta, R., Yuan, J.P., Sven, S., Eva, H., Michael, H.E. and Frank, L. (2014) Prostaglandin E2 Labour Induction with Intravaginal (Minprostin) versus Intracervical (Prepidil) Administration at Term: Randomized Study of Maternal and Neonatal Outcome and Patient's Perception Using the Osgood Semantic Differential Scales. BioMed Research International, 2014, Article ID: 682919.

https://doi.org/10.1155/2014/682919

[10] Author (2008) NICE clinical guideline 70: Induction of Labour. https://www.nice.org.uk/guidance/CG70

[11] Bahar, A.M., Archibong, E.I., Zaki, Z.M. and Mahfouz, A.A. (2003) Induction of Labour Using Low and High Dose Regimens of Prostaglandin E2 Vaginal Tablets. East African Medical Journal, 80, 51-55. https://doi.org/10.4314/eamj.v80i1.8666

[12] Deurenberg, P., Deurenberg, M. and Guricci, S. (2002) Asians Are Different from Caucasians and from Each Other in Their Body Mass Index/Body Fat Percent Relationship. Obesity Reviews, 3, 141-146. https://doi.org/10.1046/j.1467-789X.2002.00065.x

[13] Goldenberg, R.L., McClure, E.M., Bhattacharya, A.M.H.S., Groat, T.D. and Stahl, P.J. (2009) Women's Perceptions Regarding the Safety of Births at Various Gestational Ages. Obstetrics and Gynaecology, 114, 1254-1258. https://doi.org/10.1097/AOG.0b013e3181c2d6a0

[14] Michael, Y., Haglund, B., Henry, N. and Magnus, W. (1998) Fetal \& Neonatal Mortality in the Post Term Pregnancy, the Impact of Gestational Age. American Journal of Obstetrics and Gynaecology, 178, 726-731. https://doi.org/10.1016/S0002-9378(98)70482-X

[15] Roshini, R., Philip, S. and Mark, P. (2004) Does Gestation Vary by Ethnic Group? A London Based Study of over 122000 Pregnancies with Spontaneous Onset of Labour. The International Journal of Epidemiology, 33, 107-113. https://doi.org/10.1093/ije/dyg238

[16] Rayburn, W.F., et al. (1992) Intravaginal Controlled Release Prostaglandin E2 Pessary for Cervical Ripening \& Initiation of Labour at Term. Clinical Obstetrics and Gynaecology, 79, 374-379. https://doi.org/10.1097/00006250-199203000-00009

[17] Hefni, M.A. and Lewis, G.A. (1980) Induction of Labour with Vaginal PGE2 3mg Pessaries. British Journal of Obstetrics and Gynaecology, 87, 199-202. https://doi.org/10.1111/j.1471-0528.1980.tb04518.x

[18] Pez, V., Deruelle, P., Kyheng, M., Boyon, C., Clouqueur, E. and Garabedian, C. (2018) Cervical Ripening and Labor Induction: Evaluation of Single Balloon Catheter Compared to Double Balloon Catheter and Dinoprostone Insert. Gynecol Obstet Fertil Senol, 46, 570-574.

[19] Rashmi, V., Jacqueline, N. and Lynne, C. (1981) Induction of Labour with Vaginal PGE2 3mg Pessaries. Journal of Obstetrics and Gynaecology, 2, 65-70

[20] Houghton, D.J. (1982) An Evaluation of the Bishops Scoring System in Relation to a Method of Induction of Labour by Intra Vaginal Prostaglandin. Postgraduate Medical Journal, 58, 403-407. 
[21] Sanchez, R. and Dirk, E. (1988) Gaudier, Labour Induction with PGE1 Misoprostol Compared with Dinoprostone Vaginal Insert. Obstetrics and Gynaecology, 91, 319-483. 